\title{
The energy security of the Republic of Tajikistan
}

\author{
A. Akhrorova ${ }^{1}$, N. Mukimova ${ }^{1} \&$ R. Razykov ${ }^{2}$ \\ ${ }^{I}$ Department of Economics and Production Management, \\ Tajik Technical University named after acad. M. Osimi, Tajikistan \\ ${ }^{2}$ Anzob Metallurgical Company, Tajikistan
}

\begin{abstract}
Tajikistan is a mountainous country, with hydropower resources which are unique by their reserves. However, having a sharply continental climate, the country has a distinct shortage of energy in autumn and winter and a limited sales market in spring and summer time. The special role of energy in economic development and social significance of the population's access to the energy carriers predetermine a particular relevance of prediction of energy security threats and search of security measures. The paper substantiates threats of the energy security of the national economy, proposes mechanisms for their lessening and neutralization. The authors give proof of the potential energy business development in the direction of increasing exports of electric energy (power) and the strengthening of geopolitical importance of the Tajik water and energy sector.

Keywords: power engineering, energy, security, resources, indicator, wear, power, electricity tariff, potential, deficit, sustainability, management.
\end{abstract}

\section{Introduction}

One of the challenges of our time is the problem of energy security both at the national and international levels. The existence and relevance of this problem are recognized by major International forums and organizations, regulations and relevant programs of the state structures in many countries and their associations. Among the main negative trends, complicating the development of Tajikistan's power engineering, it should be noted a high level of capital fund depreciation, the lack of incentives and inefficient management. The last accompanied by a 
significant amount of non-payments for energy consumption, which in turn affect the financial stability of the energy company. It should be particularly noted the underdevelopment of market infrastructure and non-competitiveness of the energy market, non-transparency of economic activity of natural monopoly, which provokes the formation of serious threats to the energy security of the country as a whole and individual consumers.

\section{Assessment of energy security level}

Assessment of energy security, as a basis of national security, should be based not only on economic and resource assessment of the energy potential of the country, but also on its effective management. And here it is applicable, in our opinion, both cost and natural indicators that allow a comprehensive assessment of energy and resource potential and its effective involvement in the economy.

\subsection{Indicators of energy security}

The indicators of energy security should be primarily attributed to the indicators of effective and sustainable development of diversified energy complex. As measures, the following indicators can be taken:

- provision with energy resources and capability of their involvement in national economy;

- export potential of energy basis and capability of its feasibility;

- diversification of generating capacity and pent-up demand;

- production of energy in general and per capita;

- percentage of energy companies in the total production of the country;

- structure of energy investments;

- capital fund depreciation;

- level of utilization of energy production capacity;

- level of reduction of environmental pollution by energy enterprises;

- capital-labor ratio of energy sectors;

- prices and tariffs by type of energy;

- indicators of efficiency and energy savings.

Below there is given the analysis of the main indicators in respect to the conditions of the Republic of Tajikistan.

\section{Hydropower resources}

The Republic of Tajikistan is a mountainous country with unique reserves of hydropower resources. According to available estimates Tajikistan is ranked 8th in the world by potential of hydropower resources and is a top in terms of specific reserves. The total volume of hydropower resources is estimated at $527 \mathrm{TWh}$, including technically possible capacity to use is $202 \mathrm{TWh}$, and economically feasible to build $-172 \mathrm{TWh}$. The installed hydropower stations' aggregated capacity totals 4,070 MW and average annual production is about $17 \mathrm{TWh}$. Analysis of the country's provision with the energy resources and real 
access to them shows that the energy dependence of Northern Tajikistan on electricity imports is $83.8 \%$, and the country's largest energy-intensive consumer - Tajik Aluminum Company - 26\%. Naturally, for the economy of country, which is a world leader in reserves of hydropower resources for $1 \mathrm{~km}^{2}$ of territory and which ranks 3rd after Iceland and Norway on reserves per unit of population, such dependence on imports of electricity, does not testify its energy security.

\section{Export potential of the power engineering of Tajikistan}

The hydropower resource potential of Tajikistan, a considerable part of which has not yet been developed, determines the strategic direction of the country's energy development, the most important of which are the construction of large and small hydropower stations, the implementation of energy efficiency programs, and entry of domestic electric-power industry to the external market. Optimization of the structure of energy consumption in the domestic market and the introduction of new facilities will allow in the future bringing export potential of the country's electric-power industry up to 7.5-8 TWh in summer and 2-2.5 TWh in winter. Increasing exports of electricity, which ensure a steady flow of foreign currency into the country, and promote strengthening the geopolitical importance of Tajikistan's energy sector, can perform stabilizing and integrating functions in the Central Asia. From the point of view of national interests the export of electricity and energy-intensive products, the production of which the Republic of Tajikistan has expressed benefits, will be effective if it ensures maximum revenue of foreign currency at the lowest costs associated with their production and supply to the foreign market. The implemented calculations show that the electric energy (power) produced by Tajikistan's power stations, in particular by Rogun hydroelectric power station, is competitive and attractive in terms of involvement to the international trade on the external electricity market.

\section{The weak diversification of generation sources}

Electric power engineering of Tajikistan is based on the preemptive use of hydropower resources with pronounced seasonal dependence.

Domestic demand for electricity is $22 \mathrm{TWh}$ per year. Deficit of electricity, which takes place in autumn and winter, is about $5 \mathrm{TWh}$, unclaimed and not consumed hydroelectric energy reaches up to $2 \mathrm{TWh}$ in spring and summer.

\section{Investments in the power engineering of Tajikistan}

Tajikistan is among the countries which is not able to provide energy development without foreign investment. The percentage of inflow of foreign investments in the sphere of production, transmission and distribution of electricity in total volume is about $30 \%$. Figure 1 shows the dynamics of the 
annual investment in the energy sector of the Republic of Tajikistan, considerable part of which are foreign investments in the development of hydropower potential.

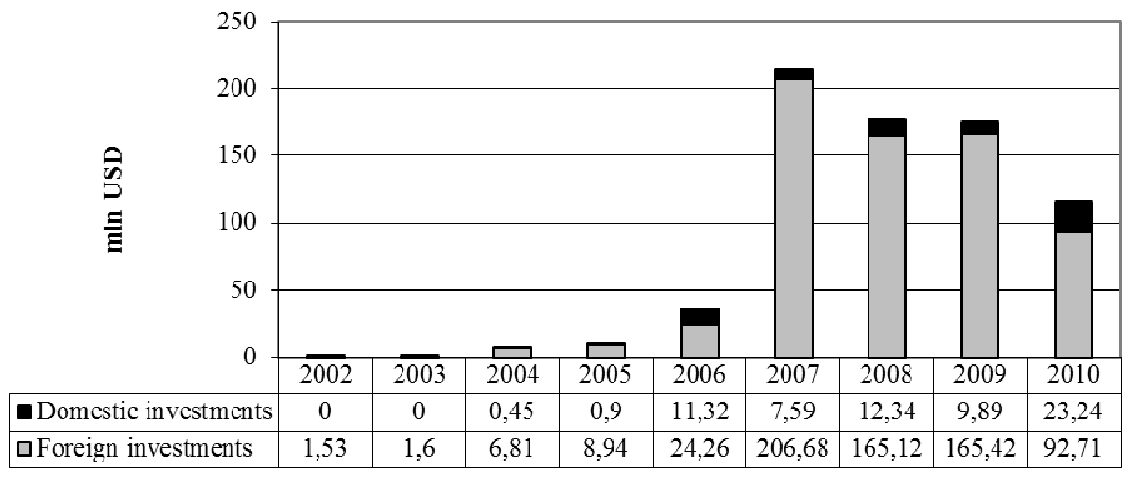

Figure 1: Dynamics of annual investments in the energy sector of Tajikistan [2].

\section{Equipment wear and lack of funds for its reparation}

High wear of capital and support equipment of generating and transporting energy of companies, loss of the useful volume of the country's largest reservoir of the Nurek hydropower station exacerbate a problem of reliable energy supply.

\section{Key contradiction}

Financial deficit, low effective demand in the domestic market, the weak diversification of energy facilities, the lack of sustainable energy ties between the agglomerations of the country, new priorities in water and energy strategies of the countries of the Central Asia, which led to limit of the abilities of realization of export electric power potential on the one hand, and infrastructure, lifesupporting nature of energy, the ever-growing energy needs on the other, identify key contradiction - inability of energy sector to provide a stable population's access to electricity, favorable conditions for the country's economic development. The acuteness of the situation causes the special relevance of the research of sustainable development of power engineering in the context of competitiveness of national economy.

\section{Global competitiveness of the economy of Tajikistan}

In the framework of the World Economic Forum there are annually compiled indexes that define each country's global competitiveness as an ability of its institutions to ensure stable economic growth. Survey questions asked for 
responses on a scale of 1 to 7 , where an answer of 1 and 7 always corresponds to the worst and best possible outcome, respectively.

The overall global competitiveness rankings of the examined 13 countries are shown in Figure 2.

Evaluation of global competitiveness of Tajikistan in terms of macroeconomic stability is 120 out of 144 countries, in terms of technological development - 114, innovative potential - 76 [1]. In terms of the overall index of global competitiveness Tajikistan ranks 100th out of 144 countries covered by the World Economic Forum. The above-stated determines the special relevance of Tajikistan's energy security in the context of improving the competitiveness of its economy. Sustainable economic development is not possible without achieving its reliable energy supply.

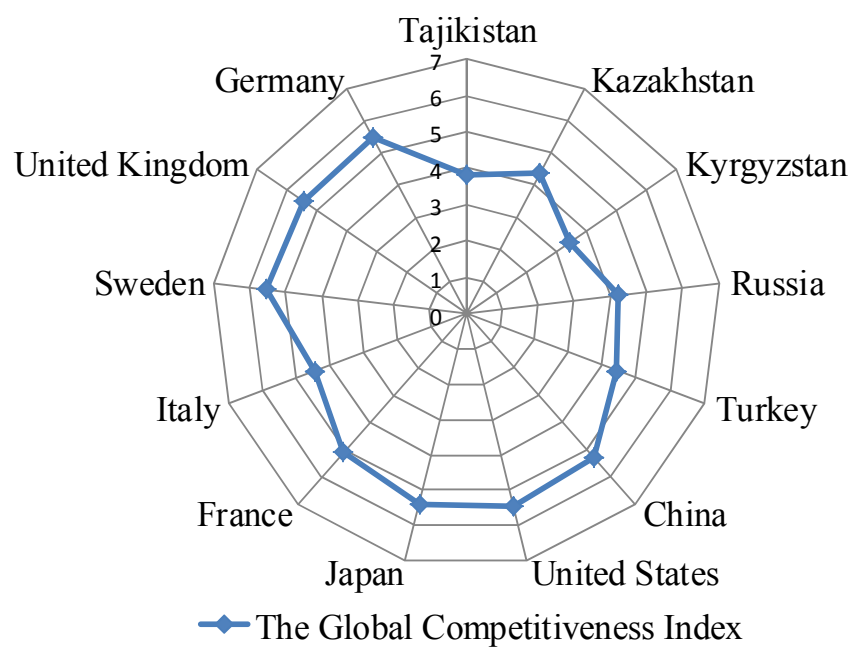

Figure 2: The Global Competitiveness Index of Tajikistan in 2012.

\section{Markets for electric energy (power)}

Uzbekistan's withdrawal from the United Central Asian Energy System (UCAES) has affected the implementation of the export potential of Tajikistan. Dynamics of imports and exports of electricity shown in Figure 3 suggests that if the export of electric energy in total production in 2007 was $27.3 \%$, then after Uzbekistan's withdrawal from UCAES, it dropped to $0.42 \%$. This has resulted in the imposition of severe restrictions on the electricity supply to consumers in the autumn-winter period.

A characteristic feature of modern environment in Central Asia is the aspiration of each country to ensure sustainable economic development, energy security. At the same time solutions at the national level is sometimes taken to the detriment of regional cooperative activity. Although international practice proved that regionalization, providing integration of economic activities in 


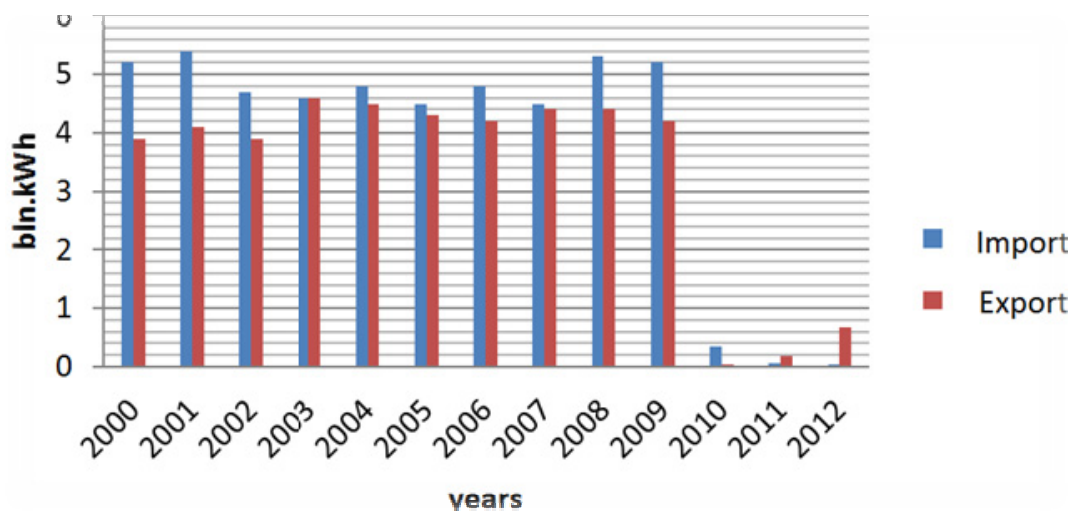

Figure 3: Dynamics of import and export of electricity.

different countries within regions, is a powerful driving factor of development in many countries and intergovernmental organizations. A striking example of the political, economic, legal and cultural regionalization is the European Union, which implements policies aimed at regulating the political, economic, social and ecological processes in the region, creating conditions for sustainable development of each country.

\subsection{Central Asian energy market as an objective necessity}

In modern conditions cooperation between the Central Asian countries, including in the areas of mutual exchange of energy resources, in new forms and new conditions may be and should be considered as objectively necessary prerequisite for their socio- economic development. It should be noted that the form and intensity of development of integration process, their effectiveness depend not only on the strength of aspiration and actions in the direction of consolidation, but also on manifestations of disintegrating factors and conditions, which oppose integration. Historical experience shows that under certain circumstances, evolving under the influence of internal and external forces, disintegrating conditions and factors can interrupt and destroy the integration processes.

\subsection{Barriers to the integration of Central Asia}

The main reasons for the lack of significant progress in integration formations in Central Asia are the inconsistency of existing in the countries of the region corresponding organization and legal basis and conditions which ensure adequate consideration of regional, national and socio-economic characteristics of each country, the necessary environment of "viability" of the consolidation. However, the existence of real common threats to the countries in the region (development of resource producing industries, international terrorism, negative consequences 
for the new sovereign states of globalization, extremism, drug trafficking, etc.) creates objective conditions for the search for an effective non-traditional models of integration, development of mutually cooperation in various fields, including water and energy sector. Experience in other countries and our own suggests that the attempt to shift the center of gravity to someone's side leads to imbalance and destruction of system stability. Typically, the one who violates this balance in their favor has only short-term gains. It is not possible to control unstable system for an extended period. Eventually, the system either collapses or eliminates the damaging effects and returns to a stable state. These processes are stretched in time and always require high material costs, and often, according to recent history of individual countries, lead to serious conflicts.

\subsection{Structure of energy consumption}

In connection with current deficit of electric power in autumn and winter period in Tajikistan, the structure of its consumers has significantly changed. If before the collapse of the unified energy system of Central Asia in consumption structure the industrial sector occupied a leading position (46\%), then since 2007 there has been a decrease in energy consumption in industry and agriculture with a simultaneous increase in the domestic sector. This trend is accompanied by very high energy intensity of the national economy, in 3-4 times exceeding the specific power-intensity of developed economies, mainly due to technological obsolescence of energy intensive industries and low consumption culture in the domestic and other non-industrial sectors. Unfortunately, current tariff system does not encourage the efficient use of energy.

\subsection{Tariff policy}

The cost of electricity in the Republic of Tajikistan increases in average by $25 \%$ per year, it is one of the conditions of implementation of energy sector reform program, developed with the assistance of international financial institutions. Currently, electricity tariffs for the population is $1.8 \mathrm{U} . \mathrm{S}$. cents per $\mathrm{kWh}$, for Tajik Aluminum Company (Talco) - 1.7 U.S. cents per kWh, for other industrial and non-industrial consumers - 4.4 U.S. cents per $1 \mathrm{kWh}$, for government organizations and communal sector -1.75 U.S. cents per $\mathrm{kWh}$, for pumping stations and electric transports - 1.18 U.S. cents per kWh. For comparison there are usually used the tariffs of some neighboring countries, which are shown in Figure 4. However, the electricity tariffs in Tajikistan and neighboring countries should be compared to purchasing power parity. At the moment the issues of formation of electricity tariffs in Tajikistan meets a number of difficulties due to the fact that people are not ready to pay for electricity at full tariffs. In addition, there should be created the possibility of financial stability of domestic energyintensive industries, which are historically focused on cheap electricity. 


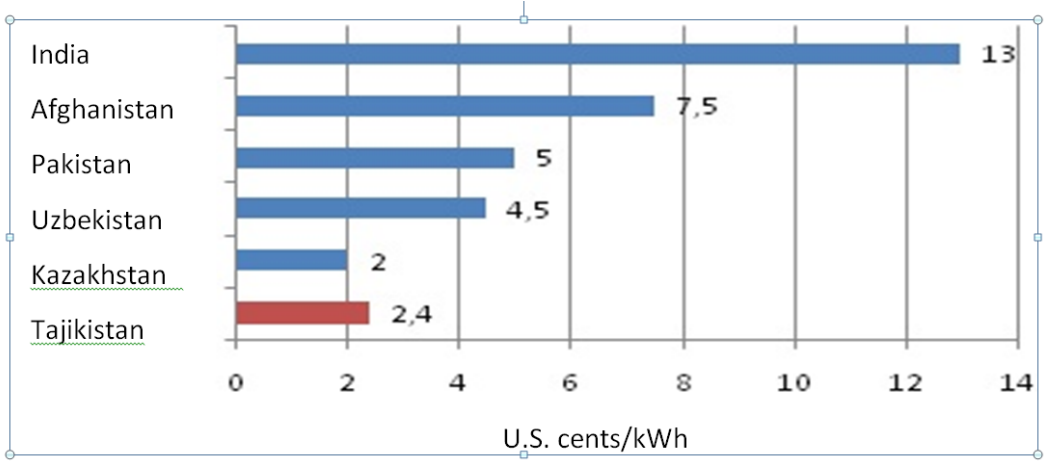

Figure 4: $\quad$ Electricity tariffs in neighboring countries.

\subsection{Relationship mechanisms of electric energy providers and consumers}

In assessing the energy security there should be considered the possibility of discrimination of consumers from energy companies. Thus, in the case of nonpayment of the necessary funds for the energy supply by the consumer in time he will be disconnected and have to pay for the connection, while the supplier, who do not provide consumers with electricity of good quality, does not consider it necessary to incur additional costs as there are no appropriate mechanisms of interaction with customer. Situation is complicated by the introduction of restrictions on access to electricity in autumn-winter period.

\section{Staffing migration as a threat of energy security}

Staffing supply of energy industry deserves special attention in the research of energy security threats. In modern conditions special significance acquires the quality of education, as well as migration. Undoubtedly, export and efficient use of labor resources can lead to qualitative changes in the transforming economy. However, there could not be ruled out the negative impact of migration on the economy in general and energy sector in particular. The implemented researches of the threats showed that the estimated number of labor migrants in Tajikistan is 1328 thousand people. In this case special attention deserves characteristic of migrants. The percentage of young segment, i.e. of 19 to 39 age bracket, is $68.5 \%$ of all migrants (Figure 5). The educational level of migrants is estimated as average (Figure 6).

About $33.3 \%$ of migrants have complete higher education, $19.4 \%$ - special education; $32.1 \%$ - completed secondary education, incomplete secondary and elementary education have $9 \%$ of migrants (Figure 7 ).

According to implemented research "the length of migrant experience" for more than $70 \%$ of migrants is more than 3 years, which is a great threat in terms of replenishment by them groups of migrants-"defectors", who in the future may lose their economic interests at home. Assuming that among migrants there are potential employees of the energy sector, the level of migration and the 


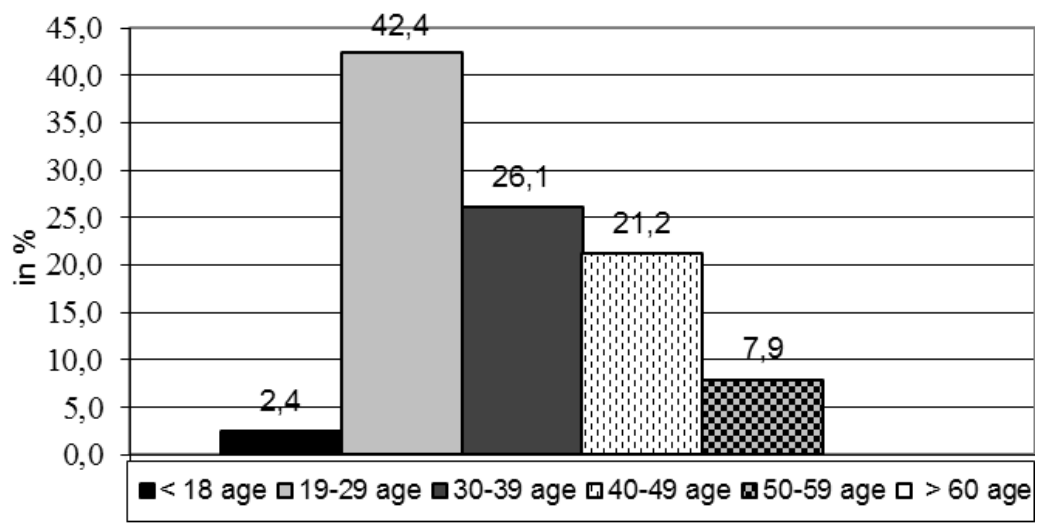

Figure 5: $\quad$ The age distribution of migrants.

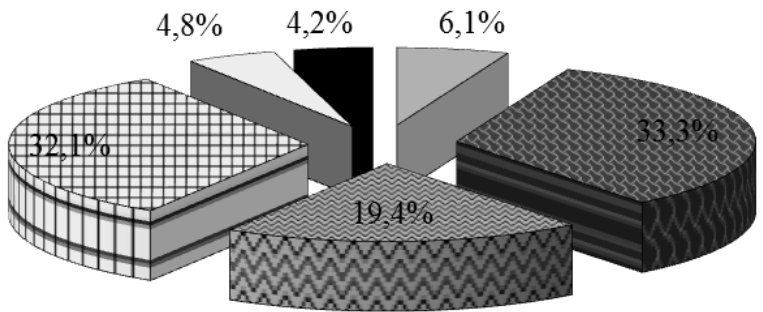

$\begin{array}{ll}\text { 口incomplete higher education } & \text { ⿴囗大 complete higher education } \\ \text { special secondary education } & \square \text { complete secondary education } \\ \square \text { imcomplete secondary education } & \mathbf{\square} \text { elementary education }\end{array}$

Figure 6: $\quad$ The education levels of migrants.

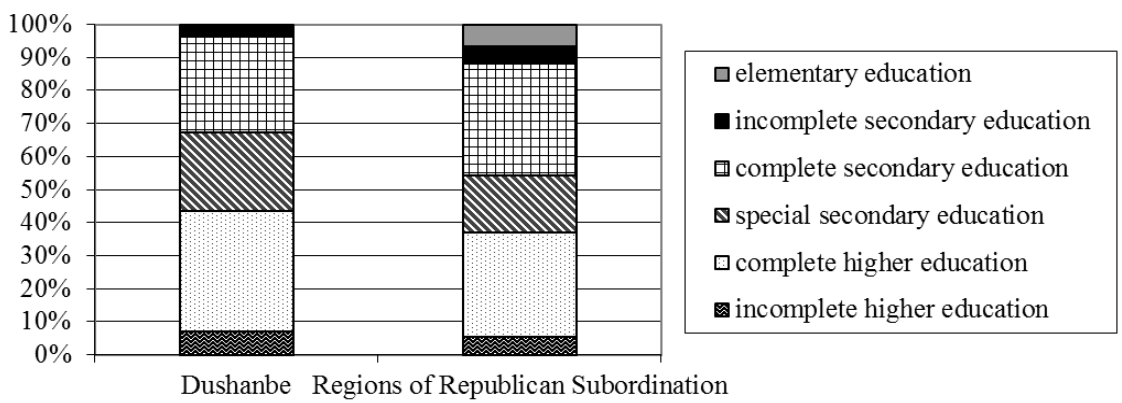

Figure 7: The educational level of the Tajik migrants from Dushanbe and RRS. 
competitiveness of the domestic energy sector have an inverse relationship. For the economy, which is based on remittance flows from abroad, it is very difficult to keep inflation rate and conduct monetary policy in general.

\section{Energy efficiency policy and the mechanism of its implementation}

In Tajikistan the problem of development and implementation of legal, administrative and economic measures system to encourage efficient use of energy is of a particular relevance. Energy conservation and energy efficiency measures should be a mandatory part of the national program of socio-economic development and energy security. In this regard, the world experience of investment resource involvement for the implementation of energy conservation programs and projects that involve companies providing energy, financial, consulting, legal, leasing, audit, and other services deserves particular value.

\section{Destabilizing effect of power engineering on the economy of Tajikistan}

Analysis of changes in the main indicators of energy security indicates that energy threats are negative and lead to the fact that the energy production sector may continue to have a destabilizing effect on the economy of the country, if the effectiveness of energy management is not increased.

\subsection{Energy security management}

Energy security, proposing reliable protection of the population and the objects of its life activity from the threat of an energy deficit of acceptable quality in normal and extreme conditions, characterizes by the level of counteracting threats of energy supply violation, expressed in one form or another. However, in our view, threats to energy security are influenced by factors determining the sustainability of energy industry development. Their scale depends on the state of the national economy and the methods of state regulation of energy supply and energy consumption. In practice, energy security means maintaining a steady energy supply of the country with all kinds of energy. To improve the efficiency of power engineering of Tajikistan, the authors propose the country's energy security management system, containing an analysis of the sensitivity and the set of sound recommendations for economy management in the event of crisis situations related to energy threats.

\section{References}

[1] The Global Competitiveness Report 2012-2013. Table 4: The Global Competitiveness Index 2012-2013. www.weforum.org

[2] Development strategies and investment policies program. Joint-stock holding company "Barki Tojik" 2010. 